\title{
Desempenho e características de carcaça de bovinos de corte de quatro grupos genéticos terminados em confinamento
}

\author{
Saulo Malaguido Clímacoํㅜㄹ Edson Luis de Azambuja Ribeiro², Ivone Yurika Mizubuti², Leandro \\ das Dores Ferreira da Silva ${ }^{2}$, Marco Aurélio Alves de Freitas Barbosa ${ }^{2}$, Ana Maria Bridi ${ }^{2}$ \\ ${ }^{1}$ Programa de Pós-Graduação em Ciência Animal da Universidade Estadual de Londrina. \\ 2 Departamento de Zootecnia da Universidade Estadual de Londrina.
}

RESUMO - Este trabalho foi desenvolvido com o objetivo de avaliar o desempenho em confinamento de animais puros das raças Tabapuã (T), Bonsmara (B), mestiços 1/2 Bonsmara $+1 / 2$ Nelore (B1) e mestiços 1/2 Bonsmara $+1 / 4$ Red Angus $+1 / 4$ Nelore (B2). Foram utilizados cinco bovinos castrados de cada grupo genético, com idade média de 22 meses e peso vivo de $394 \pm 21 \mathrm{~kg}$, ao início do experimento. A dieta para todos os animais continha silagem de cana-de-açúcar e ração comercial na proporção de 55 e 45\% (base seca), respectivamente, com 14,99\% de PB e 59,84\% de NDT. Os animais foram abatidos quando atingiram escore visual de acabamento de 3 , numa escala de $1=$ magros a $5=$ obesos. Houve efeito significativo dos grupos genéticos sobre o consumo de matéria seca, cujas médias foram de 1,9;2,1;2,2 e 2,2\% do PV, respectivamente, para os animais Tabapuã, Bonsmara, B1 e B2. O ganho médio diário em peso vivo dos animais cruzados B1 (0,925 kg) e B2 (1,122 kg) e puros Bonsmara $(1,035 \mathrm{~kg})$ foi superior ao dos animais da raça Tabapuã $(0,630 \mathrm{~kg})$, que foram mais tardios para atingir escore corporal de abate. O consumo de nutrientes, como porcentagem do peso vivo ou por unidade de peso metabólico, não diferiu entre grupos genéticos. Carcaças de animais Bonsmara apresentaram melhor escore de conformação, porém as carcaças dos animais da raça Tabapuã tiveram melhores médias para rendimento de carcaça quente (56,2\%) e fria (55,2\%). Não houve diferença no peso de carcaça fria entre os grupos genéticos. Animais Bonsmara puros, B1 e B2, apresentam melhor desempenho em confinamento em comparação aos Tabapuã.

Palavras-chave: consumo, cruzamento, ganho de peso, rendimento de carcaça

\section{Performance and carcass traits of four genetic groups of beef cattle steers finished in feedlot}

\begin{abstract}
The objective of this work was to evaluate feedlot performance of Tabapuã (T) and Bonsmara (B) purebreed animals, and 1/2 Bonsmara $+1 / 2$ Nelore (B1) and 1/2 Bonsmara $+1 / 4$ Red Angus $+1 / 4$ Nelore (B2) crossbred animals It was used five castrated bovines from each genetic group at average age of 22 months and live weight of $394 \pm 21 \mathrm{~kg}$ at the beginning of the experiment. The diet for all the animals contained sugar cane silage and commercial ration at the proportion of 55 and 45\% (dry matter basis), respectively, with 14.99\% CP and 59.84\% TDN. Animals were slaughtered when they reached a visual finishing body score of 3 , in a scale from $1=$ thin to $5=$ obese. There was a significant effect of genetic groups on dry matter intake, whose averages were 1.9, 2.1, 2.2 and 2.2\% BW for Tabapuã, Bonsmara, B1 and B2 animals, respectively. Average daily gain in live weight of crossbred animals B1 (0.925 kg) and B2 (1.122 kg) and purebred Bonsmara $(1.035 \mathrm{~kg})$ were greater than the ones of Tabapuã (0.630 kg), which were the latest to reach body condition score for slaughtering. Nutrient intake, as percentage of the body weight or per unit of metabolic weight, did not differ among genetic groups. Carcasses of Bonsmara animals presented the best conformation score, but carcasses of Tabapuã animals obtained the best means for hot (56.2\%) and for cold (55.2\%) dressing percentages. There was no difference for cold carcass weight among the genetic groups. Purebred Bonsmara steers, B1 and B2, presented better fedlot performances in comparison to Tabapuã steers.
\end{abstract}

Key Words: crossbreding, dressing percentages, intake, weight gain

\section{Introdução}

A viabilidade econômica da produção de bovinos de corte no Brasil está diretamente relacionada ao sistema de produção adotado. As pastagens, os grupos genéticos e os sistemas de exploração utilizados em regiões tropicais diferem muito daqueles empregados nas regiões de clima temperado. Assim, existe a necessidade de se desenvolver tecnologia apropriada à realidade brasileira (Alves et al., 2004). 
A busca por genótipos adaptados às nossas condições de clima e com características produtivas semelhantes à dos animais europeus, provenientes de processos de seleção seculares, é um objetivo da pecuária de corte (Euclides Filho \& Figueiredo, 2003). Ainda segundo esses autores, a utilização do cruzamento industrial entre raças zebuínas e raças taurinas aumenta a produtividade por meio da heterose e da combinação aditiva, que pode estar presente tanto para características adaptativas (Bos indicus e Bos taurus adaptado) quanto para algumas produtivas (Bos taurus).

A raça Bonsmara foi desenvolvida com o objetivo de aproveitar o vigor e a rusticidade do gado nativo e a produtividade das raças britânicas. O Afrikaner, gado nativo da África do Sul, foi a base para formação da raça. A raça Bonsmara foi obtida quando os cruzamentos atingiram grau de sangue com 5/8 Afrikaner e 3/8 Raças europeias (Hereford ou Shorthorn) (ABCB, 2009; Barca Junior et al., 2008). Segundo a ABCB (2009), para a formação de animais Bonsmara Puros de Origem, podem ser usados cruzamentos absorventes onde o grupamento B1 corresponde aos mestiços Bonsmara $\times$ Nelore ou Raça europeia $\times$ Bonsmara, e o grupamento $\mathrm{B} 2$ ao resultado do cruzamento $\mathrm{B} 1 \times$ Bonsmara.

A raça Tabapuã (Bos indicus) teve origem a partir de um touro Nelore cruzado com vacas Nelore, Guzerá e Gir, apresentando o diferencial de ser mocha. Apresenta qualidades de boa habilidade materna e adaptabilidade a diversas regiões (ABC, 1997). De acordo com Jorge et al. (1998), apresenta desempenho similar ao de outras raças zebuínas (Nelore, Guzerá e Gir) criadas no Brasil.

Na busca da precocidade, as mudanças que vem ocorrendo na cadeia produtiva da carne em geral e nos sistemas de produção, em particular, indicam a necessidade de se promover novas avaliações, considerando-se, além do ganho de peso, características de carcaça (Rubiano et al., 2009).

Este trabalho foi desenvolvido com o objetivo de avaliar o desempenho em confinamento e as características de carcaça de bovinos Bonsmara, puros e mestiços e Tabapuã.

\section{Material e Métodos}

O experimento foi conduzido na Fazenda Barbacena, município de São Pedro do Ivaí, Região Noroeste do Estado do Paraná. Foram utilizados 20 bovinos, cinco de cada grupo genético, machos castrados, com idade média de 22 meses e peso vivo de $394 \pm 21 \mathrm{~kg}$, ao início do experimento. Todos os animais apresentavam escore de condição corporal 2, em uma escala de 1 a 5 (Machado et al., 2008); onde 1 = muito magros ou caquéticos (processos transversos e espinhosos e costelas bem visíveis; cauda totalmente inclusa dentro do coxal e íleos e ísquios mostram-se expostos; atrofia muscular), 2 = magros (ossos bastante salientes, com certa proeminência dos processos dorsais e dos íleos e dos ísquios; costelas têm pouca cobertura; processos transversos visíveis; cauda menos inclusa nos coxais), 3 = médio (cobertura muscular suave; processos dorsais pouco visíveis; costelas quase cobertas; processos transversos pouco aparentes), 4 = gordo (boa cobertura muscular, com alguma deposição de gordura na inserção da cauda; costelas e processos transversos completamente cobertos; regiões individuais do corpo ainda são bem definidas; partes angulares do esqueleto menos identificáveis), e 5 = muito gordo ou obeso (ângulos do corpo cobertos, incluindo as partes salientes do esqueleto, onde aparecem camadas de gordura; partes individuais do corpo difíceis de ser distinguidas e o animal tem aparência arredondada).

Os bovinos foram mantidos em confinamento durante todo o período experimental e foram distribuídos aleatoriamente em baias individuais cobertas. Os grupos genéticos testados foram: 1) Bonsmara (B); 2) 1/2 Bonsmara $+1 / 2$ Nelore (B1); 3) $1 / 2$ Bonsmara $+1 / 4$ Red Angus $+1 / 4$ Nelore (B2); e 4) Tabapuã (T). Os animais passaram por um período prévio de adaptação às instalações e à dieta a partir da terceira semana antes do início do experimento.

O período experimental total foi de 119 dias, com pesagens, após jejum de sólidos, a intervalos médios de 28 dias. Todavia, os animais foram abatidos quando o grupo atingia escore de condição corporal médio igual a 3. Os animais B1 e Bonsmara foram abatidos após 100 dias de confinamento, os B2 após 106 dias, e os Tabapuã aos 119 dias. O alimento foi fornecido duas vezes ao dia, às $8 \mathrm{~h} \mathrm{e}$ às 17 h30.

A relação volumoso:concentrado, na matéria seca da ração foi de 55:45. O volumoso utilizado foi a silagem de cana-de-açúcar e o concentrado uma ração comercial, constituída por farelo de trigo, melaço, milho grão, resíduo de soja, farelo de soja, uréia pecuária, calcário calcítico, múltiplo vitamínico, múltiplo mineral e sal comum. A quantidade de alimento fornecida aos animais foi ajustada para se obter em torno de 5 a 10\% de sobras de alimento no cocho, a qual era pesada diariamente, pela manhã. A mistura do concentrado ao volumoso foi feita diariamente em vagão misturador (Tabela 1).

Diariamente foram pesadas e colhidas amostras da dieta e das sobras para análises laboratoriais e para os cálculos do consumo. As análises das amostras dos alimentos e das sobras foram realizadas no Laboratório de Nutrição Animal da Universidade Estadual de Londrina. Foram determinadas as porcentagens de matéria mineral, proteína bruta, extrato etéreo e fibra bruta pelo método de Wendee, e fibra em detergente ácido e fibra em detergente 
Tabela 1 - Composição química bromatológica da dieta experimental

\begin{tabular}{lc}
\hline Composição da ração total & \% na matéria seca \\
\hline Matéria seca & 53,92 \\
Proteína bruta & 14,99 \\
Extrato etéreo & 1,40 \\
Fibra bruta & 27,32 \\
Matéria mineral & 6,54 \\
Extrato não-nitrogenado & 48,80 \\
Fibra em detergente neutro & 56,83 \\
Fibra em detergente ácido & 35,12 \\
Nutrientes digestíveis totais ${ }^{1}$ & 59,84 \\
\hline
\end{tabular}

${ }^{1}$ Calculado de acordo com McDowell et al. (1974).

neutro pelo método de Van Soest, conforme citado por Silva \& Queiroz (2002). O teor de nutrientes digestíveis totais (NDT) foi estimado de acordo com McDowell et al. (1974).

Para o abate, os animais foram enviados para frigorífico comercial, onde foram insensibilizados por concussão cerebral, com pistola de dardo cativo, seguido por sangria pela secção das artérias parótidas e veias jugulares. Imediatamente após o abate, as meias-carcaças foram identificadas e pesadas, sendo posteriormente mantidas em câmara fria por 24 horas a $2^{\circ} \mathrm{C}$, e então foram novamente pesadas para se obter o rendimento de carcaça fria e a quebra ao resfriamento. As carcaças foram avaliadas conforme proposto por Muller (1987) e, em cada meiacarcaça, foi medido o comprimento interno, correspondente à distância entre o bordo anterior do púbis e o bordo anterior medial da primeira costela. Também foram medidos o comprimento de perna (medida da distância entre a articulação tíbio-tarsiana e o bordo anterior do púbis), o comprimento de braço (medida da distância entre o olécrano e a articulação rádio-carpiana), o perímetro de braço (medida envolvendo o braço à metade de seu comprimento), a espessura de coxão, com o auxílio de um compasso, a profundidade da carcaça (distância entre o dorso e o esterno) e a compacidade da carcaça (peso de carcaça fria/ comprimento de carcaça).
As carcaças também foram classificadas de acordo com conformação, de 1 a 6 , sendo 1 = carcaça com cobertura muscular muito pobre, côncava; 2 = sub-côncava; 3 = côncava, com proeminência de apófises ósseas; 4 = carcaça retilínea; 5 = sub-convexa; e 6 = carcaça convexa, a mais musculosa; e de acordo com o acabamento, classificadas de 1 a 5 , sendo 1 = carcaça com ausência de gordura; 2 = carcaça com gordura escassa; 3 = carcaça com gordura mediana; 4 = carcaça com gordura uniforme; e 5 = carcaça com gordura excessiva (adaptado de Muller, 1987; Luchiari, 2000).

Como os animais dos diferentes tratamentos foram abatidos com diferentes períodos de confinamento e como as carcaças frias pesavam em média $260 \mathrm{~kg}$, foram também calculados o tempo necessário para atingir 260 kg de carcaça, com base no ganho médio diário apresentado, e o peso vivo necessário para atingir este peso de carcaça, com base no rendimento de carcaça fria apresentada.

Os dados obtidos foram submetidos à análise de variância para um modelo inteiramente casualizado, tendo como variável independente o efeito de grupo genético, sendo considerado o nível de significância de 5\% de probabilidade (SAS, 1994). As diferenças entre médias foram comparadas pelo teste de Tukey.

\section{Resultados e Discussão}

Os animais Bonsmara e mestiços Bonsmara (B1 e B2) foram significativamente superiores aos Tabapuã em ganho médio diário, consumo de matéria seca e conversão alimentar, atingindo um peso de abate mais elevado, mesmo para um menor tempo de confinamento (Tabela 2).

Menezes \& Restle (2005), trabalhando com bovinos de diferentes composições genéticas, zebuíno (Nelore) e taurino (Charolês), também observaram maior consumo de matéria seca entre os animais mestiços, além de apresentarem maiores pesos quando comparados aos puros. Comparando animais com a mesma faixa etária e das

Tabela 2 - Características de desempenho de bovinos de quatro grupos genéticos

\begin{tabular}{|c|c|c|c|c|c|}
\hline \multirow[t]{2}{*}{ Variável } & \multicolumn{4}{|c|}{ Grupo genético } & \multirow[t]{2}{*}{$\operatorname{Pr}>F$} \\
\hline & B1 & B2 & Bonsmara & Tabapuã & \\
\hline Peso inicial, kg & $400 \pm 10$ & $412 \pm 10$ & $375 \pm 10$ & $388 \pm 11$ & 0,0810 \\
\hline Peso final, kg & $484 \pm 5 b$ & $511 \pm 6 a$ & $497 \pm 6 a b$ & $463 \pm 6 c$ & 0,0003 \\
\hline Ganho médio diário, kg & $0,925 \pm 0,08 a$ & $1,122 \pm 0,08 \mathrm{a}$ & $1,035 \pm 0,09 a$ & $0,630 \pm 0,09 b$ & 0,0031 \\
\hline Consumo de MS, kg & $9,9 \pm 0,3 \mathrm{ab}$ & $10,1 \pm 0,3 a$ & $9,2 \pm 0,3 b$ & $8,2 \pm 0,3 c$ & 0,0039 \\
\hline Consumo de MS, \%PV & $2,2 \pm 0,1 \mathrm{a}$ & $2,2 \pm 0,1 \mathrm{a}$ & $2,1 \pm 0,1 \mathrm{ab}$ & $1,9 \pm 0,1 b$ & 0,0305 \\
\hline Consumo de $\mathrm{MS}, \mathrm{PV}^{0,75}$, g & $102 \pm 3 a$ & $102 \pm 3 a$ & $96 \pm 3 a b$ & $87 \pm 3 b$ & 0,0185 \\
\hline Conversão alimentar & $10,7 \pm 0,4 b$ & $9,0 \pm 0,4 a$ & $8,9 \pm 0,4 a$ & $12,9 \pm 0,4 c$ & 0,0002 \\
\hline Dias $260 \mathrm{~kg}^{1}$ & $106 \pm 12 \mathrm{ab}$ & $104 \pm 13 a b$ & $98 \pm 13 a$ & $141 \pm 13 b$ & 0,0117 \\
\hline $\mathrm{PV}-260 \mathrm{~kg}^{2}$ & $490 \pm 4 b$ & $506 \pm 4 a$ & $493 \pm 4 b$ & $471 \pm 4 c$ & 0,0004 \\
\hline
\end{tabular}

B1 = 1/2 Bonsmara + 1/2 Nelore, B2 = 1/2 Bonsmara + 1/4 Red Angus + 1/4 Nelore. MS = matéria seca; PV = peso vivo.

${ }^{1}$ Dias em confinamento para atingir $260 \mathrm{~kg}$ de carcaça fria. ${ }^{2}$ Peso vivo necessário para produzir uma carcaça fria com $260 \mathrm{~kg}$.

a, b, c - Médias na linha seguidas por letras diferentes diferem entre si $(P<0,05)$. 
raças Canchim e Aberdeen Angus, Perotto et al. (2002) observaram desempenhos similares para a conversão alimentar. Houve, no entanto, diferença quanto ao consumo de matéria seca por unidade de peso vivo, com maiores valores verificados nos animais da raça Aberdeen Angus e maior ganho médio diário de peso em confinamento para os animais da raça Canchim. Goulart et al. (2008) comparando animais de diversos grupos genéticos oriundos de cruzamentos com Nelore, observaram maior ganho de peso nos animais $1 / 2$ Aberdeen Angus $+1 / 2$ Nelore, e atribuíram este desempenho ao maior consumo de matéria seca. Por outro lado, Alves et al. (2004), avaliando cruzas de animais taurinos e zebuínos, não observaram diferenças significativas sobre o ganho médio diário, mesmo com maiores consumos de matéria seca apresentados pelos animais com grau de sangue taurino.

Os novilhos Tabapuã necessitaram de 43 dias a mais $(\mathrm{P}<0,05)$ para produzir o mesmo peso de carcaça que os novilhos puros Bonsmara. Os três grupos genéticos com sangue Bonsmara tiveram ganhos de acordo com a dieta elaborada, que visava o ganho diário de $1,0 \mathrm{~kg}$ por dia (NRC, 1996). Porém, os animais do grupo genético Tabapuã apresentaram ganho $37 \%$ menor do que o esperado. De acordo com Menezes \& Restle (2005), o menor ganho de peso apresentado por animais zebuínos se deve, em parte, a menor capacidade de ingestão de alimentos, fato observado no presente trabalho. Menezes et al. (2007) observaram que novilhos com maior proporção de sangue zebuíno apresentaram menor capacidade do trato digestório.

Ganhos de peso superiores para animais taurinos, ou mestiços com taurinos, comparados com zebuínos foram encontrados por alguns pesquisadores (Menezes \& Restle, 2005; Cruz et al., 2009). Por outro lado, Goulart et al. (2008) não observaram diferenças entre novilhos Nelore e F1 Nelore/Simental ou Canchim.

De acordo com Kippert et al. (2008), o desempenho de bovinos oriundos de cruzamentos se deve aos efeitos da heterose individual e materna, fatos estes que provavelmente explicam o melhor desempenho dos animais B1 e B2, quando comparados aos Tabapuã neste estudo.

Por outro lado os diferentes desempenhos podem estar relacionados com a seleção para ganho de peso que os grupos genéticos, ou rebanhos dentro de raça, receberam nas gerações anteriores. Este fato foi sugerido por Jorge et al. (1998) quando compararam o desempenho de quatro raças zebuínas, e observaram que os animais Nelore apresentaram maior ganho de peso em comparação aos Tabapuã, e justificaram esta diferença pela seleção mais intensa para produtividade que a raça Nelore foi submetida.

Apesar dos valores para conversão alimentar serem altos (mínimo de 9 e máximo de 13), estão de acordo com os resultados $(9,5)$ apresentados por Pinto et al. (2009), para bovinos alimentados com cana-de-açúcar, onde a mesma representava aproximadamente $40 \%$ da dieta oferecida.

Para o consumo de nutrientes, as únicas diferenças observadas foram para consumo em kg de FDA e NDT (Tabela 3), estando diretamente relacionados com o consumo de matéria seca. O maior consumo de energia foi o responsável pelo maior ganho de peso dos animais Bonsmara e cruzados Bonsmara (B1 e B2).

Os animais Bonsmara apresentaram pesos de carcaça quente significativamente $(\mathrm{P}<0,05)$ maiores que os

Tabela 3 - Consumo de nutrientes de bovinos de quatro grupos genéticos

\begin{tabular}{|c|c|c|c|c|c|}
\hline \multirow[t]{2}{*}{ Variável } & \multicolumn{4}{|c|}{ Grupo genético } & \multirow[t]{2}{*}{$\operatorname{Pr}>\mathrm{F}$} \\
\hline & B1 & B2 & Bonsmara & Tabapuã & \\
\hline Proteína bruta, kg & $1,5 \pm 0,1$ & $1,6 \pm 0,1$ & $1,4 \pm 0,1$ & $1,3 \pm 0,1$ & 0,1917 \\
\hline Proteína bruta, $\mathrm{PV}^{0,75}$, g & $16 \pm 1$ & $16 \pm 1$ & $15 \pm 1$ & $13 \pm 1$ & 0,3557 \\
\hline Extrato etéreo, kg & $0,14 \pm 0,03$ & $0,14 \pm 0,03$ & $0,13 \pm 0,03$ & $0,12 \pm 0,03$ & 0,8837 \\
\hline Extrato etéreo, \%PV & $0,03 \pm 0,01$ & $0,03 \pm 0,01$ & $0,03 \pm 0,01$ & $0,03 \pm 0,01$ & 0,9579 \\
\hline Fibra bruta, \%PV & $0,60 \pm 0,05$ & $0,59 \pm 0,05$ & $0,57 \pm 0,05$ & $0,51 \pm 0,05$ & 0,5817 \\
\hline Fibra bruta, $\mathrm{PV}^{0,75}$, g & $28 \pm 2$ & $27 \pm 2$ & $26 \pm 2$ & $23 \pm 2$ & 0,5180 \\
\hline Fibra em detergente ácido, kg & $3,7 \pm 0,2 \mathrm{a}$ & $3,9 \pm 0,2 \mathrm{a}$ & $3,5 \pm 0,2 \mathrm{ab}$ & $3,1 \pm 0,2 b$ & 0,0351 \\
\hline Fibra em detergente ácido, \%PV & $0,85 \pm 0,04$ & $0,84 \pm 0,04$ & $0,80 \pm 0,04$ & $0,73 \pm 0,04$ & 0,1378 \\
\hline Fibra em detergente ácido, $\mathrm{PV}^{0,75}$, g & $39 \pm 2$ & $39 \pm 2$ & $37 \pm 2$ & $33 \pm 2$ & 0,1000 \\
\hline Fibra em detergente neutro, kg & $5,4 \pm 0,3$ & $5,6 \pm 0,3$ & $5,0 \pm 0,3$ & $4,4 \pm 0,3$ & 0,0839 \\
\hline
\end{tabular}

B1 $=1 / 2$ Bonsmara $+1 / 2$ Nelore, $B 2=1 / 2$ Bonsmara $+1 / 4$ Red Angus $+1 / 4$ Nelore. $a$, $b$ - Médias na linha seguidas por letras diferentes diferem entre si $(\mathrm{P}<0,05)$. 
animais B1 (1/2 Bonsmara + 1/2 Nelore) e Tabapuã (Tabela 4), não diferindo dos animais B2 (1/2 Bonsmara + 1/4 Red Angus $+1 / 4$ Nelore). Todavia, não foram observadas diferenças significativas $(\mathrm{P}<0,05)$ para os pesos de carcaça fria entre os quatro grupos genéticos deste estudo. Os animais Tabapuã, seguidos dos B1, apresentaram os maiores rendimentos de carcaça fria. Menezes \& Restle (2005) atribuíram à menor capacidade do trato digestório de animais zebuínos os melhores resultados de rendimento de carcaça. Leite et al. (2006), comparando animais $100 \%$ taurinos e com crescentes graus de sangue zebuíno, também não observaram diferenças nos pesos médios das carcaças.

Os animais Bonsmara apresentaram melhor conformação das carcaças (Tabela 5). Tal diferença também foi observada por Santos et al. (2008), que obtiveram melhores pontuações para conformação para as carcaças dos animais mais jovens e pertencentes a grupos genéticos com maior grau de sangue taurino. As raças taurinas geralmente apresentam maior musculosidade e conformação de carcaça (Euclides Filho \& Figueiredo, 2003).

Entre os grupos genéticos não foi observada diferença para o parâmetro acabamento de gordura, o qual apresentou distribuição regular sobre toda a superfície das carcaças. Estes resultados estão de acordo com o critério de abate utilizado, onde os animais foram abatidos quando atingiram o mesmo acabamento, avaliado subjetivamente nos animais vivos. Para as demais medidas mensuradas nas carcaças (Tabela 5), apenas o perímetro de braço foi influenciado pelo grupo genético, sendo que os animais Bonsmara apresentaram as maiores médias, e diferiram apenas dos animais B1. Esta característica, além de estar relacionada com a musculosidade da carcaça, também, é relacionada com precocidade sexual dos animais, pois animais com maior atividade dos hormônios masculinos apresentam anteriores mais desenvolvidos (Ribeiro et al., 2004). Sendo que todos os animais deste experimento foram castrados em torno de um mês antes do início do experimento.

Tabela 4 - Produção de carcaça de bovinos de quatro grupos genéticos

\begin{tabular}{|c|c|c|c|c|c|}
\hline \multirow[t]{2}{*}{ Variável } & \multicolumn{4}{|c|}{ Grupo genético } & \multirow[t]{2}{*}{$\operatorname{Pr}>F$} \\
\hline & B1 & B2 & Bonsmara & Tabapuã & \\
\hline Peso de carcaça quente, kg & $260 \pm 2 b$ & $266 \pm 2 \mathrm{ab}$ & $268 \pm 2 a$ & $260 \pm 2 b$ & 0,0094 \\
\hline Peso de carcaça fria, kg & $257 \pm 2$ & $262 \pm 2$ & $262 \pm 2$ & $256 \pm 2$ & 0,0723 \\
\hline Rendimento de carcaça quente, \% & $53,9 \pm 0,4 b$ & $52,2 \pm 0,4 c$ & $53,9 \pm 0,4 b$ & $56,2 \pm 0,4 a$ & 0,0001 \\
\hline Rendimento de carcaça fria, \% & $53,1 \pm 0,4 b$ & $51,4 \pm 0,4 c$ & $52,8 \pm 0,4 \mathrm{bc}$ & $55,2 \pm 0,4 a$ & 0,0002 \\
\hline Quebra ao resfriamento, \% & $1,5 \pm 0,2$ & $1,6 \pm 0,2$ & $2,0 \pm 0,3$ & $1,8 \pm 0,3$ & 0,0671 \\
\hline
\end{tabular}

B1 = 1/2 Bonsmara $+1 / 2$ Nelore, B2 = 1/2 Bonsmara $+1 / 4$ Red Angus $+1 / 4$ Nelore. $a, b, c-$ Médias na linha seguidas por letras diferentes diferem entre si (P $<0,05)$.

Tabela 5 - Características de carcaça de bovinos de quatro grupos genéticos

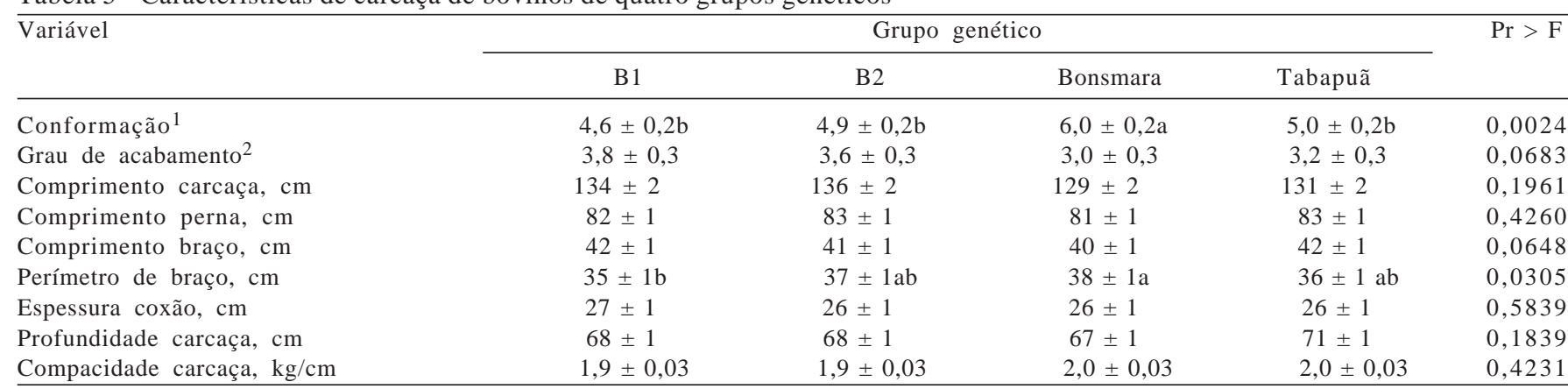

B1 = 1/2 Bonsmara $+1 / 2$ Nelore, B2 = 1/2 Bonsmara $+1 / 4$ Red Angus $+1 / 4$ Nelore

${ }^{1}$ Classificadas de 1 a 6 , sendo 1 = carcaça com cobertura muscular muito pobre, côncava; 4 = carcaça retilínea; $5=$ subconvexa; e $6=$ carcaça convexa, a mais musculosa.

${ }^{2}$ Classificadas de 1 a 5 , sendo 1 = carcaça com ausência de gordura; 2 = carcaça com gordura escassa; 3 = carcaça com gordura mediana; 4 = carcaça com gordura uniforme; e 5 = carcaça com gordura excessiva.

a, b - Médias na linha seguidas por letras diferentes diferem entre si $(\mathrm{P}<0,05)$.

\section{Conclusões}

Animais Bonsmara, puros e mestiços, podem ser recomendados para sistemas intensivos de produção de gado de corte no Brasil, pois, além de bom desempenho em confinamento, também apresentam carcaças e carne de qualidade. Os animais da raça Tabapuã, por sua vez, podem ser usados com o objetivo de melhorar o item rendimento de carcaça, em rebanhos brasileiros. 


\section{Agradecimentos}

Ao Conselho Nacional de Pesquisa e Desenvolvimento (CNPq), pelas bolsas de produtividade em pesquisa de Ribeiro e Mizubuti.

\section{Referências}

ALVES, D.D.; PAUlinO, M.F.; BACKES, A.A. et al. Desempenho produtivo de bovinos Zebu e cruzados Holandês-Zebu nas fases de recria e terminação. Acta Scientiarum, v.26, n.3, p.385-391, 2004

ASSOCIAÇÃO BRASILEIRA DOS CRIADORES - ABC. Tabapuã: a história de uma nova raça. Revista dos Criadores, v.67, n.803, p.12-18, 1997.

ASSOCIAÇÃO BRASILEIRA DOS CRIADORES DE BONSMARA - ABCB. [2009]. A raça. Disponível em: <http://www.bonsmara. org.br/araca1.htm.> e <http://www.bonsmara.org.br/araca9. htm>. Acesso em: 1 out. 2009.

BARCA JUNIOR, F.A.; OKANO, W.; THOMAZELLA, E.Z. et al. Determinação das frequencies genotípicas alélicas do polimorfismo de hemoglobina em bovines da raça Bonsmara no norte do estado do Paraná. Arquivos de Ciências Veterinárias e Zoologia da Unipar, v.11, n.1, p.31-34, 2008.

CRUZ, G.M; RODRIGUES, A.A.; TULLIO, R.R. et al. Desempenho de bezerros da raça Nelore e cruzados desmamados recebendo concentrado em pastagem adubada de Cynodon dactylon cv. Coastcross. Revista Brasileira de Zootecnia, v.38, n.1, p.139-148, 2009.

EUCLIDES FILHO, K.; FIGUEIREDO, G.R. Retrospectiva e perspectivas de cruzamentos no Brasil. In: SIMPOSIO BRASILEIRO SOBRE CRUZAMENTO INDUSTRIAL, 1., 2003, Londrina. Anais... Londrina: IAPAR, 2003. p.11-35.

GOULART, R.S.; ALENCAR, M.M.; POTT, E.B. et al. Composição corporal e exigências líquidas de proteína e energia de bovinos de quatro grupos genéticos terminados em confinamento. Revista Brasileira de Zootecnia, v.37, n.5, p.926-935, 2008.

JORGE, A.M.; FONTES, C.A.A.; PAULINO, M.F. et al. Desempenho produtivo de animais de quatro raças zebuínas, abatidos em três estádios de maturidade. 1. Ganho de peso e de carcaça e eficiência de ganho. Revista Brasileira de Zootecnia, v.27, n.4, p.766-769, 1998.

KIPPERT JUNIOR, C.; RORATO, P.R.N.; LOPES, J.S. et al. Efeitos genéticos aditivos diretos e maternos e heterozigóticos sobre os desempenhos pré e pós-desmame em uma população multirracial Aberdeen Angus x Nelore. Revista Brasileira de Zootecnia, v.37, n.8, p.1383-1391, 2008.

LEITE, D.T.; ARBOITTE, M.Z., BRONDANI, I.L. et al. Composição física da carcaça e qualidade da carne de bovinos superjovens inteiros Charolês e mestiços Charolês x Nelore. Acta Scientiarum, v.28, n.4, p.461-467, 2006.
LUCHIARI, A.F. Pecuária da carne bovina. São Paulo: A. Luchiari Filho, 2000. 134p.

MACHADO, R.; CORRÊA, R.F.; BARBOSA, R.T. et al. Escore da condição corporal e sua aplicação no manejo reprodutivo de ruminantes. São Carlos: EMBRAPA, 2008. 16p. (Circular Técnica, 57).

McDOWELL, L.R.; CONRAD, J.H.; THOMAS, J.E. et al. Tabelas de composição de alimentos da América Latina. Gainesville: Universidade da Flórida, 1974. 47p.

MENEZES, L.F.G.; RESTLE, J. Desempenho de novilhos de gerações avançadas do cruzamento alternado entre as raças Charolês e Nelore, terminados em confinamento. Revista Brasileira de Zootecnia, v.34, n.6, p.1927-1937, 2005.

MENEZES, L.F.G.; RESTLE, J.; BRONDANI, I.L. et al. Órgãos internos e trato gastrintestinal de novilhos de gerações avançadas de cruzamento rotativo entre as raças Charolês e Nelore terminados em confinamento. Revista Brasileira de Zootecnia, v.36, n.1, p.120-129, 2007.

MÜLLER, L. Normas para avaliação de carcaças e concurso de carcaças de novilhos. 2.ed. Santa Maria: Universidade Federal de Santa Maria, 1987. 31p.

NATIONAL RESEARCH COUNCIL - NRC. Nutrient requirements of beef cattle. 7. rev. ed. Washington, D.C.: National Academy Press, 1996. 242p.

PEROTTO, D.; MOLETTA, J.L.; LESSKIU, C. Desempenho em confinamento de machos bovinos inteiros Canchim, Aberdeen Angus e cruzamentos recíprocos. Ciência Rural, v.32, n.4, p.669-674, 2002.

PINTO, A.P.; NASCIMENTO, W.G.; ABRAHÃO, J.J.S. et al. Digestibilidade, consumo, desempenho e características de carcaça de tourinhos mestiços confinados com cana-de-açúcar ou silagem de sorgo. Revista Brasileira de Zootecnia, v.38, n.11, p.2258-2263, 2009.

RIBEIRO, E.L.A.; HERNANDEZ, J.A.; ZANELLA, E.L. et al. Growth and carcass characteristics of pasture fed LHRH imunocastrated, castrated and intact Bos indicus bulls. Meat Science, v.68, n.2, p.285-290, 2004.

RUBIANO, G.A.G.; ARRIGONI, M.B.; MARTINS, C.L. et al. Desempenho, características de carcaça e qualidade da carne de bovinos superprecoces das raças Canchim, Nelore e seus mestiços. Revista Brasileira de Zootecnia, v.38, n.12, p.2490-2498, 2009.

SANTOS, A.P.; BRONDANI, I.L.; RESTLE, J. Características quantitativas da carcaça de novilhos jovens e superjovens com peso de abate similares. Ciência Animal Brasileira, v.9, n.2, p.300-308, 2008.

SILVA, D.J.; QUEIROZ, A.C. Análise de alimentos: métodos químicos e biológicos. 3.ed. Viçosa, MG: UFV, 2002. 235p.

STATISTICAL ANALYSIS SYSTEM - SAS. SAS/STAT user's guide. Cary: SAS Institute Inc., 1994. v.2. (CD-ROM). 